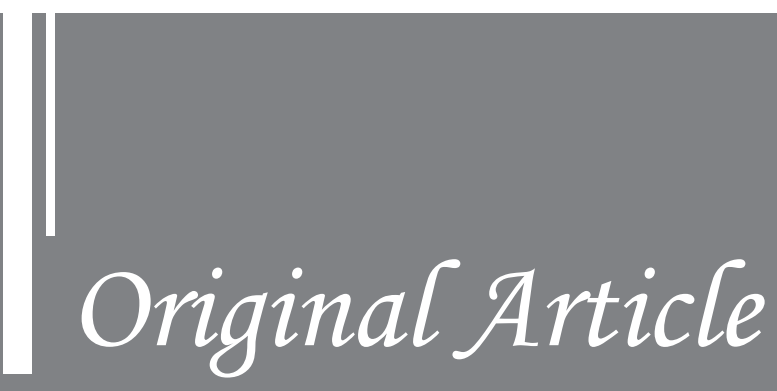

\title{
EPIDEMIOLOGICAL INVESTIGATIONS OF ACUTE WATERY DIARRHEA OUTBREAK DURING JULY- AUGUST 2017 IN AMARPURA, RAWALPINDI - PAKISTAN
}

\section{Khurram Shahzad Akram ${ }^{1}$, Muhammad Wasif Malik ${ }^{1 \& 2}$, Mumtaz Ali Khan', Majid Ail Tahir ${ }^{2}$,Syeda Shazia Adeel', Mirza Amir Baig ${ }^{1}$}

'Field Epidemiology \& Laboratory Training Program - Pakistan

${ }^{2}$ National Institute of Health, Islamabad

Correspondence: MumtazAli Khan, Email: drmomi74@hotmail.com

\begin{abstract}
Background: On July 24, 2017, two cases suspected of acute watery diarrhea (AWD) were reported from tertiary care hospital, Rawalpindi. District health authorities directed to conduct outbreak investigation, identified risk factors and recommend control measures.

Methods: A descriptive followed by age-sex matched case control study (1:3) was done from Jul 27 to Aug 02, 2017. Case definition was "sudden onset of loose watery stools (? 3 in past $24 \mathrm{hrs}$ ) with any of symptoms i.e. vomiting, nausea, abdominal cramps or fever in residents of Amar Pura from July 19 to August 02, 2017". Active and passive case finding technique were done in addtion to hosptial record review. Total 02 stool and 03 water samples were collected for microbiological testing. Odd ratios computed on $95 \%$ confidence interval and $P$ value $<0.05$.

Results: Total 18 cases were identified (mean age: 16 year; range: $02 \mathrm{~m}-55 \mathrm{yrs}$ ), predominate were male 2.6:1. Overall attack rate (AR) was 7.2/1000 and preponderate affected age group was 15-24 years (AR: 10/1000). Significantly associated risk factors were; use of untreated municipal water (OR:15, CI: 4.00-73.96) and use of untreated well water (OR:14.52, CI: 3.98-59.99). Use of water from filtration plant was found protective association (OR: 0.12, CI: 0.005-0.750). Laboratory found Vibrio Cholera Serotype Inaba in stool samples and coliforms in water samples.

Conclusion: Consumption of contaminated water was most probable cause of outbreak. Use of filtered water was found to be a protective measure. Chlorination of water sources and health awareness sessions on water sanitation and hygiene were done in community.

Keywords: Acute Watery Diarrhea, outbreak investigation, water borne illness
\end{abstract}




\section{Introduction}

Globally, a leading cause of morbidity and mortality among children is Diarrhea. Mostly it is caused by contaminated food and water. Diarrhea is present in three clinical forms: acute watery diarrhea, acute bloody diarrhea, and persistent diarrhea. Developing countries are majorly affected by Diarrhea having infectious origin. In children below five years of age Diarrhea is ranked as second major cause of mortality and accounts for 525,000 deaths annually (1). A major portion of these cases occur in the developing countries and more than half of childhood diarrhea cases happen in Asia and Africa having 1.2 billion cases and 696 million cases accordingly. While rest of the world experience 480 million cases (2).

Acute diarrhea is a type of illness in which patient passes three or more loose or liquid stools per day in a period of not more than 14 days and if diarrhea last for 14 days or more then it can be classified as dysentery or persistent diarrhea. The other symptoms present in the include vomiting, fever, and body weakness. There is loss of fluid and electrolytes from the body of patient due to passage of loose or watery stools resulting in dehydration. In more severe cases in which dehydration is not controlled then patient can die also (3).

The diarrhea can be caused by bacteria, virus or parasites. The main bacteria responsible for causing diarrhea are Vibrio cholerae, Escherichia coli, Campylobacter Jejuni, Salmonella and Shigella species while types of virus causing diarrhea are rotavirus, adenovirus, and corona viruses. The common parasitic agents responsible for diarrhea include Entamoeba, and Giardia (4). It was estimated by World Health Organization that 780 million population of the world had lack of access to better-quality drinking-water while 2.5 billion people lack improved sanitation (1).

On July 24, 2017, Field Epidemiology \& Disease Surveillance Division (FEDSD), National Institute of Health Islamabad (NIH) informed Federal Disease Surveillance and Response Unit (FDSRU) about a laboratory confirmed stool sample for acute watery diarrhea (AWD). The case was already admitted in Pediatric Isolation ward in Benazir Bhutto Hospital, Rawalpindi. A team of FELTP fellows was assigned to conduct outbreak investigation in the affected area of Amarpura, Rawalpindi on July 27, 2017, where the case belonged. The objectives of the outbreak investigation were to assess magnitude of the outbreak, to study risk factors associated with the outbreak and to recommend measures for prevention and control outbreak.

\section{Case definitions}

A case definition for outbreak investigation was developed as "Sudden onset of loose watery stools (? 3 in past 24 hours) with any of the symptoms like vomiting, nausea, abdominal cramps or fever in a resident of Amar Pura District Rawalpindi from July 19, 2017 to August 2, 2017. The confirmation was on laboratory result or epidemiological linkage with positive case."

\section{Methodology}

Epidemiological investigations for outbreak with active case finding from door to door was carried out and then case-control study was conducted in Amarpura, Rawalpindi. All residents of outbreak affected area were included in this study.A total number of 500 houses in the area of Amarpura, Rawalpindi, were probably affected by outbreak of acute watery diarrhea. The estimated population included in this study was calculated to be 2500 persons of all ages. A semi-structured questionnaire was developed to take data during outbreak investigation. The questionnaire contained questions related to demographic characteristics, clinical features and risk factor information. The information for laboratory findings and environmental assessment was also incorporated in the questionnaire. All residents of the outbreak affected area of Amarpura, Rawalpindi were included in the study. Temporary residents i.e. guests who were present in the affected area during the time period of disease outbreak were also included in this study. All residents, both permanent and temporary, of Amarpura, Rawalpindi who were not present in the outbreak affected area during period of outbreak were excluded from the study. All temporary residents i.e. guests of Amarpura, Rawalpindi who were present in the outbreak affected area but not during the time period of disease outbreak were also excluded from the study. Record review of Benazir Bhutto Hospital, Rawalpindi was carried out for hospital admission during period of outbreak i.e. from July 19, 2017 to August 02, 2017. All the cases under the case definition were reviewed and sorted from the record of three units i.e. Pediatrics unit, Emergency ward and Medical ward. A total No. of 02 stool samples from suspected cases in relation to case definition of acute watery diarrhea were taken in Cary Blair medium and sent to National Institute of Health, Islamabad isolation and identification of V. cholera. Water samples $(03$ No.) from municipal water supply lines, well in the house and municipal water filtration plant were also taken and sent to National Institute of Health, Islamabad for isolation and identification of coliforms as indicative organisms for fecal contamination of the water. Data was collected from cases on a semi-structured questionnaire as per case definition. Age and sex matched controls were taking in 1:3 and their data was also collected on same questionnaire. This questionnaire was also used to take information regarding laboratory testing and environmental assessment. The data was entered in MS Excel and it was analyzed by Epi Info (Version 7). Descriptive analysis was carried out, cases were classified into age-groups, and attack rates were calculated. Risk factor analysis was carried and odd ratios were calculated at confidence interval of $95 \%$ and $\mathrm{P}$ value $<0.05$.

Results

An epidemiological investigation of the outbreak of acute watery diarrhea (AWD) was started from July 27, 2017 and a total 18 cases in number were identified by conducting hospital record review and door to door active case finding among residents of Amarpura, District Rawalpindi. The probable area affected by outbreak had 500 houses with an estimated population of 2500 person. Mean age of the cases was 16.36 year (range: 02 months to 55 years). Male to female ratio among cases was 2.6:1 and male found more affected $(n=13,72.2 \%)$.

The cases were distributed into age-groups and it was found that there were 03 cases in $0-5$ years age group, 03 cases in 5-15 years age group, 09 cases in 15-25 years age group and 3 cases in 25 years and above age-group (Figure-1).

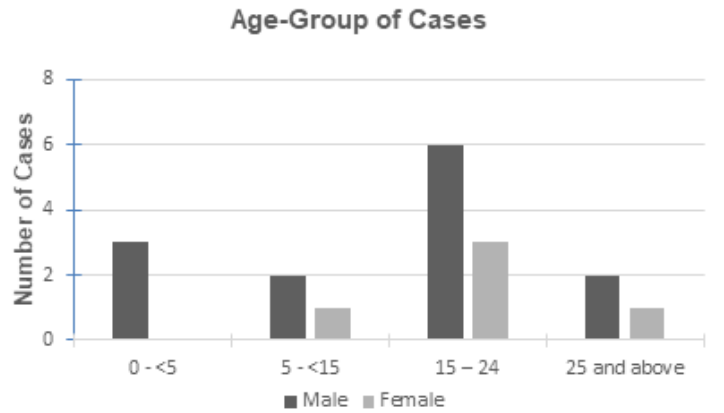

Figure-1: Age-wise distribution of acute watery diarrhea (AWD) cases during July to August 2017 in Amarpura, Rawalpindi Attack Rates

The most affected age group was 15-24 years with attack rate of 10 cases per 1000 population followed by age group of 25 years and above with attack rate of 08 cases per 1000 population. The overall attack rate in the affected area was 7.2 cases per 1000 population. The data for age groups, no. of cases and attack rates is presented in Table-1.

Table-1: Age-groups, Case Distribution \& Attack Rates of acute watery diarrhea (AWD) cases during July to August 2017 in Amarpura, Rawalpindi

\begin{tabular}{|c|c|c|c|c|c|c|c|c|c|}
\hline \multirow{2}{*}{$\begin{array}{l}\text { Age } \\
\text { Group } \\
\text { s } \\
\text { (Years) }\end{array}$} & \multicolumn{6}{|c|}{ Cases } & \multirow{2}{*}{$\begin{array}{l}\text { Tota } \\
1\end{array}$} & \multirow[t]{2}{*}{$\%$} & \multirow[t]{2}{*}{$\mathbf{A R}$} \\
\hline & Male & $\%$ & $\mathbf{A R}$ & Female & $\%$ & $\mathbf{A R}$ & & & \\
\hline $0-4$ & 3 & $\begin{array}{l}17 \\
\%\end{array}$ & 0.70 & 0 & $0 \%$ & 0 & 3 & $17 \%$ & 0.70 \\
\hline $5-14$ & 2 & $\begin{array}{l}11 \\
\%\end{array}$ & 0.25 & 1 & $6 \%$ & 0.12 & 3 & $17 \%$ & 0.37 \\
\hline $15-24$ & 6 & $\begin{array}{l}33 \\
\%\end{array}$ & 0.66 & 3 & $\begin{array}{l}17 \\
\%\end{array}$ & 0.33 & 9 & $50 \%$ & 0.99 \\
\hline $\begin{array}{l}25 \text { and } \\
\text { above }\end{array}$ & 2 & $\begin{array}{l}11 \\
\%\end{array}$ & 0.53 & 1 & $5 \%$ & 0.26 & 3 & $16 \%$ & 0.79 \\
\hline Total & 13 & $\begin{array}{l}72 \\
\%\end{array}$ & 0.52 & 5 & $\begin{array}{l}28 \\
\%\end{array}$ & 0.2 & 18 & $\begin{array}{l}100 \\
\%\end{array}$ & 0.72 \\
\hline
\end{tabular}

Epi-Curve for the outbreak

First case of acute watery diarrhea was found on July 24, 2017 , followed by 03 more cases on July 25, 2017 while cases peaked on July 
26, 2017. No case was reported after July 28, 2017 (Figure-2).

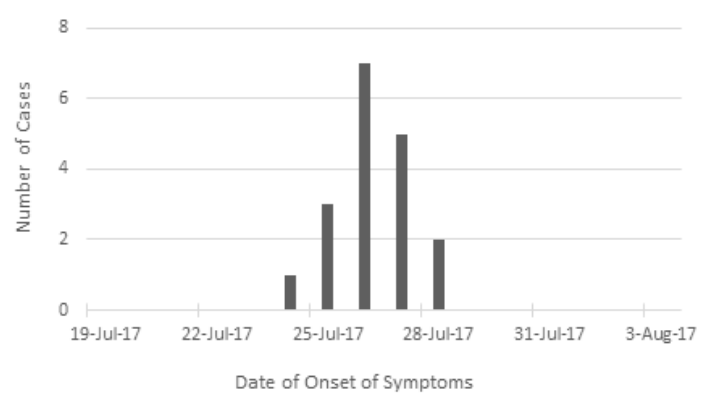

Figure-2: Distribution of acute watery diarrhea (AWD) cases as per date of onset of symptoms during July to August 2017 in Amarpura, Rawalpindi

Clinical Feature of the cases

All the cases $n=18(100 \%)$ were found to have loose watery stools, abdominal pain and dehydration, a total of $93 \%$ cases had vomiting and myalgia while $03 \%$ cases experienced blood in stools. None of the cases was found to cellulitis and bullae. The frequency of distribution of clinical features amongst cases are shown in Figure-3.

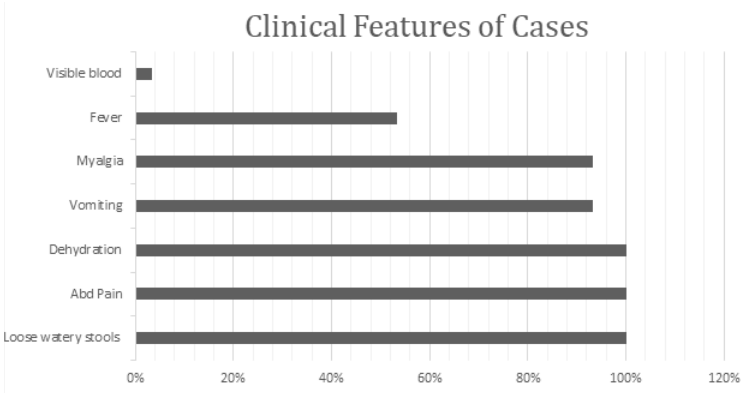

Figure-3: Clinical feature of acute watery diarrhea (AWD) cases during July to August 2017 in Amarpura, Rawalpindi Laboratory Findings

Stool samples (02 No.) were collected from the suspected cases and sent to National Institute of Health, Islamabad. The results showed that V. Cholera (Inaba strain) in both samples. Water samples (03 No.) were collected from different points in the outbreak affected area. The samples were sent to National Institute of Health, Islamabad for microbial analysis. It was found that all water samples were contaminated with coliforms and well water samples were having more microbial load as compared to filtration plant samples. The results are tabulated in Table-2:

Table-2: Microbial load in water samples of acute watery diarrhea (AWD) cases during July to August 2017 in Amarpura, Rawalpindi

\begin{tabular}{|l|l|l|l|l|}
\hline S. No. & Bacteriological Analysis & Well Water & $\begin{array}{l}\text { Public Water } \\
\text { Supply }\end{array}$ & $\begin{array}{l}\text { Filtered } \\
\text { Water }\end{array}$ \\
\hline 1 & $\begin{array}{l}\text { Most probable number of } \\
\text { coliform organisms per } 100 \mathrm{ml}\end{array}$ & 240 & 0 & 2 \\
\hline 2 & $\begin{array}{l}\text { Confirmed fecal coliform per } \\
100 \mathrm{ml}\end{array}$ & 240 & 0 & 2 \\
\hline 3 & $\begin{array}{l}\text { Confirmed E. coli count per 100 } \\
\mathrm{ml}\end{array}$ & 20 & 0 & 2 \\
\hline $\mathbf{4}$ & Results & Unsatisfactory & Satisfactory & Unsatisfactory \\
\hline
\end{tabular}

Environmental Assessment

On environmental assessment of outbreak affected area it was found that Amarpura was a thickly populated and very congested area. Major population of Amarpura belong to middle to low socio-economic class. There were three types of water system in practice by local community; well water, untreated municipal water and municipal filtration plant. Untreated municipal water was supplied to homes through pipelines while municipal administration installed a filtration plant to supply filtered drinking water to local community. Most of the resident of Amarpura use to take drinking water from filtration plant installed by municipal administration. The water tanks in houses were not clean and were in bad condition. Water pipelines in houses were rusty. There was not proper sewerage system in the area. The overall hygiene and sanitation condition of the outbreak area was very poor.

Analysis of risk factors

A case-control study was carried out to study risk factors associated with spread of disease in the area. Age and sex matched controls were taken from the same area and for each case three (03) controls were taken. Univariate analysis revealed that risk factors significantly associated with spread of disease in the affected area were use of untreated municipal water (OR: 15.03, 95\%CI: 4.00-73.96, $\mathrm{P}<0.00)$, and use of untreated well water (OR: 14.52, 95\%CI: 3.98-59.99, $\mathrm{P}<0.00$ ). On risk factor analysis, it was found that population using water supplied by municipal filtration plant was not affected with this outbreak (OR: 0.12, 95\% CI: 0.005-0.750, $\mathrm{P}<0.00)$. The results of risk factor analysis are tabulated in Table-3.

Table 3: Analysis of risk factors for acute watery diarrhea (AWD) cases during July to August 2017 in Amarpura, Rawalpindi

\begin{tabular}{|c|c|c|c|c|}
\hline \multicolumn{5}{|c|}{ Risks Factors for Acute Watery D iarrhea Outbreak } \\
\hline Risk Factors & Cases n (\%) & \begin{tabular}{|l|} 
Controls \\
n (\%)
\end{tabular} & Odd Ratio (95\%CI) & P-value \\
\hline $\begin{array}{l}\text { Use of un -treated } \\
\text { water } \\
\text { - Yes } \\
\text { - No }\end{array}$ & $\begin{array}{l}15(83.33 \%) \\
03(16.67 \%)\end{array}$ & $\begin{array}{l}13(24.07 \%) \\
41(75.93 \%)\end{array}$ & $15.03(4.00-73.96)$ & 0.00 \\
\hline $\begin{array}{l}\text { Use of untreated } \\
\text { well water } \\
\text { - Yes } \\
\text { - No }\end{array}$ & $\begin{array}{l}11(61.11 \%) \\
07(38.89 \%)\end{array}$ & $\begin{array}{l}05(9.26 \%) \\
49(90.74 \%)\end{array}$ & $14.52(3.98-59.99)$ & 0.00 \\
\hline $\begin{array}{l}\text { Use of water from } \\
\text { municipal } \\
\text { filtration plant } \\
\text { - Yes } \\
\text { - No }\end{array}$ & $\begin{array}{l}01(5.56 \%) \\
17(94.44 \%)\end{array}$ & $\begin{array}{l}18(33.33 \%) \\
36(66.67 \%)\end{array}$ & $0.12(0.005-0.750)$ & 0.00 \\
\hline
\end{tabular}

\section{Control Measures Taken}

The Municipal administration was informed about the incidence to take the control measures. Water disinfection medicine for treatment of water tanks of houses were distributed in the area while cleaning and chlorination of municipal water tanks were carried out. The suspected cases were taken to hospital for proper health care. Follow up visits were conducted to identify any new case of AWD and to monitor the effectiveness of control measures. No new cases were reported after July 28, 2017.

Discussion

The results of this study suggests that use of untreated water either from municipal water supply system or from well inside the house resulted in cases of acute watery diarrhea. The results of this study have similarity with a case control study carried out in Uganda which found that use of water without boiling or any other treatment resulted outbreak of acute watery diarrhea (6). The coliforms are main culprits for contamination of water (7) and are believed to be major contributors for diarrheal diseases. The results of this study showed that untreated municipal supply water and water from well were contaminated with coliforms The consumption of contaminated water by residents of Amarpura, Rawalpindi resulted in cases of acute watery diarrhea. A study was carried out by a researcher from Emory University, USA also found that risk of diarrhea increase with increasing level of coliforms in drinking water (8). The environmental assessment of outbreak affected area was carried out as a part of epidemiological investigations of our study and it was revealed that hygiene conditions and sanitation practices were poor in the area. The water storage tanks were not clean, the water pipelines were rusty and proper sewerage system was not present. These conditions were the possible factors for spread of disease. These findings of our study are supported by a study carried out to estimate burden of diarrheal diseases due to sanitation and hygiene in low and middle income areas (9).

The usage of safe and clean water is a key measure for prevention of diarrhea. Study observations reveal that the people in study locality consuming water from municipal filtration plants stayed safe from the outbreak. The possible reason for this is that water filtration plant removed fecal contaminants which are the main cause for diarrheal diseases. A randomized controlled trial study was conducted in Bolivia in which researchers used ceramic water filters at house hold level. This intervention resulted in removal of fecal contaminants from drinking water which consequently reduced burden of diarrheal diseases (10). 
Hence, results of existing studies are supporting the findings of our study that use of filtered water decrease the incidence of diarrheal diseases.

Conclusion

It is concluded from the epidemiological investigations of outbreak that most males were more affected gender group while the most affected age-group was 15-24 years. The most probable reason of outbreak was use of untreated water either supplied by municipal administration or taken from well / bore of a house. The residents who used water from filtration plant installed by municipal administration were not affected by this outbreak. The other reason for outbreak and spread of disease was poor hygiene and sanitation condition of the area. The water storage tanks were not clean, the water supply pipelines were rusty and there was no proper sewerage system in the area.

The key measures to prevent acute diarrhea include better hygiene conditions, improved sanitation practices, and access to clean drinking water. The provision of oral re-hydration, micronutrient supplementation and good supportive care are required to manage patients of diarrhea.

It was recommended that municipal administration should make plan for preventive maintenance and periodic cleaning of the water supply system and also of filtration plant. The broken and rusty water pipelines should be replaced while proper chlorination of the water as per recommended standard operating procedure (SOP) should be carried out. The surveillance system should be strengthened for early detection of cases and prevention of any major outbreak. It was also recommended that water disinfection medicine should be distributed periodically to residents of Amarpura, Rawalpindi. The municipal administration should also carry out regular water testing to detect any untoward change in the water quality and to take early control measures.

Funding: No financial funds were taken from any quarter for this research or for writing of this manuscript. Field Epidemiology \& Laboratory Training Program, Pakistan (FELTP) provided technical guidance and support. National Institute of Health (NIH), Pakistan carried out all laboratory tests free of cost.

Conflict of Interest: There is no conflict of interest of any person or any organization with this research.

\section{Reference}

1. World Health Organization. WHO $\mid$ Diarrhoeal disease [Internet]. WHO website. 2012. Available from: http://www.who.int/ mediacentre/factsheets/fs330/en/index.html
2. Fischer Walker CL, Rudan I, Liu L, Nair H, Theodoratou E, Bhutta ZA, et al. Global burden of childhood pneumonia and diarrhoea. Lancet. 2013;381(9875):1405-16.

3. Grimwood K, Forbes DA. Acute and Persistent Diarrhea. Pediatr Clin North Am [Internet]. 2009 Dec;56(6):1343-61. Available from: http://linkinghub.elsevier.com/retrieve/pii/ S0031395509001187

4. Maponga BA, Chirundu D, Gombe NT, Tshimanga M, Shambira G, Takundwa L. Risk factors for contracting watery diarrhoea in Kadoma City, Zimbabwe, 2011: A case control study. BMC Infect Dis. 2013;13(1).

5. Kumar SG, Subitha L. Diarrhoeal diseases in developing countries: a situational analysis. Kathmandu Univ Med J (KUMJ) [Internet]. 2012;10(38):83-8. Available from: http://www.ncbi.nlm.nih.gov/pubmed/23132483

6. Kwesiga B, Pande G, Ario AR, Tumwesigye NM, Matovu JKB, Zhu B-P. A prolonged, community-wide cholera outbreak associated with drinking water contaminated by sewage in Kasese District, western Uganda. BMC Public Health [Internet]. 2017;18(1):30. Available from: http://www.ncbi.nlm.nih.gov/ pubmed/28720083

7. Pandey, K.P., Kass, H. P., Souqir, L.M. and Singh, P.V. Contamination of water resources by pathogenic bacteria. ABM Express, 2014. Vol. 4, Issue 51

8. Hodge J, Chang HH, Boisson S, Collin SM, Peletz R, Clasen T. Assessing the Association between Thermotolerant Coliforms in Drinking Water and Diarrhea: An Analysis of Individual-Level Data from Multiple Studies. Environ Health Perspect [Internet]. 2016 Oct;124(10):1560-7. Available from: http://www.ncbi.nlm.nih.gov/pubmed/27164618

9. Prüss-Ustün A, Bartram J, Clasen T, Colford JM, Cumming O, Curtis V, et al. Burden of disease from inadequate water, sanitation and hygiene in low- and middle-income settings: a retrospective analysis of data from 145 countries. Trop Med Int Health [Internet]. 2014 Aug;19(8):894-905. Available from: http://www.ncbi.nlm.nih.gov/pubmed/24779548

10. Clasen TF, Brown J, Collin S, Suntura O, Cairncross S. Reducing diarrhea through the use of household-based ceramic water filters: A randomized, controlled trial in rural Bolivia. Am J Trop Med Hyg. 2004;70(6):651-7. 